\title{
Elaboração e validação de escala diagramática para quantificação da severidade da antracnose em frutos de maracujá amarelo
}

\author{
Ivan Herman Fischer ${ }^{1}$, Silvio André Meirelles Alves ${ }^{2}$, Aparecida Marques de Almeida ${ }^{1}$, Maria Cecília de Arruda ${ }^{1}$, \\ Rosemary Marques de Almeida Bertani ${ }^{1}$, Maria José De Marchi Garcia ${ }^{1}$
}

\begin{abstract}
${ }^{1}$ Agência Paulista de Tecnologia dos Agronegócios, Av. Rodrigues Alves 40-40, 17030-000, Bauru, SP; ${ }^{2}$ Embrapa Uva e Vinho, Rod. BR 285, km 115, 95200-000, Vacaria, RS.

Autor para correspondência: Ivan Herman Fischer (ihfische@gmail.com)

Data de chegada: 28/08/2007. Aceito para publicação em: 29/06/2009

\section{RESUMO}

Fischer, I.H.; Alves, S.A.M.; Almeida, A.M.; Arruda, M.C.; Bertani, R.M.A.; Garcia, M.J.M. Elaboração e validação de escala diagramática para quantificação da severidade da antracnose em frutos de maracujá amarelo. Summa Phytopathologica, v.35, n.3, p.226-228, 2009

Uma escala diagramática foi desenvolvida com o intuito de padronizar a avaliação da severidade da antracnose em frutos de maracujá amarelo, causada por Colletotrichum gloeosporioides. A escala foi elaborada considerando os limites máximos e mínimos de severidade da doença. Os valores percentuais de sintomas de antracnose seguiram incrementos $\operatorname{logarítmicos}(1,3,8,21,44$ e $70 \%$ ). Para a validação da escala, dez avaliadores (cinco inexperientes e cinco experientes) quantificaram a severidade da

doença, sem e com o uso da escala, a partir de 50 frutos com diferentes níveis de doença. As avaliações com a escala diagramática foram mais precisas e acuradas nas estimativas da maioria dos avaliadores, e proporcionaram maior reprodutibilidade entre avaliações dos avaliadores. A escala diagramática proposta foi considerada adequada para estimar a severidade da antracnose em frutos de maracujá amarelo e poderá ser utilizada em estudos epidemiológicos e de controle desta doença.
\end{abstract}

Palavras-chave adicionais: Passiflora edulis, Colletotrichum, patometria.

\section{ABSTRACT}

Fischer, I.H.; Alves, S.A.M.; Almeida, A.M.; Arruda, M.C.; Bertani, R.M.A.; Garcia, M.J.M. Elaboration and validation of diagrammatic scale to evaluate anthracnose severity in yellow passion fruits. Summa Phytopathologica, v.35, n.3, p.226-228, 2009

A diagrammatic scale was developed to standardize severity assessments of anthracnose on yellow passion fruit, caused by Colletotrichum gloeosporioides. The scale was elaborated considering the maximum and minimum limits of disease severity. The percentile values for anthracnose symptoms followed logarithmic increments $(1,3,8,21,44$ e $70 \%)$. To validate the scale, ten raters (five inexperienced and five experienced) quantified the disease severity, without and using the scale, of 50 fruits with anthracnose symptoms. Assessments with the diagrammatic scale had higher precision and accuracy for majority of raters, besides being more reproducible among raters. The proposed diagrammatic scale was considered adequate to estimate anthracnose severity in yellow passion fruits and could be used in epidemiological and control studies.

Keywords: Passiflora edulis, Colletotrichum, pathometry.

A antracnose, causada por Colletotrichum gloeosporioides (Penz. \& Sacc.), é comumente encontrada nas regiões produtoras de maracujá amarelo (Passiflora edulis f. flavicarpa Deg.) do Brasil, reduzindo o valor comercial dos frutos e o seu período de comercialização. Os frutos apresentam manchas pardo-claras que com o amadurecimento aumentam em tamanho, evoluindo para uma podridão mole e deprimida, atingindo grande extensão do fruto (7).

A quantificação de doenças, quer seja pela incidência ou pela severidade, é fundamental para estudos epidemiológicos e de manejo. $\mathrm{Na}$ avaliação da antracnose do maracujazeiro têm sido utilizadas apenas escalas descritivas, que apresentam limitações por serem subjetivas e não permitirem um ajuste da acuidade visual na avaliação dos níveis de severidade (2). Diante disso, a avaliação da severidade da doença com o auxílio de uma escala diagramática, representando frutos com diferentes porcentagens de área ocupadas pelas lesões, é uma excelente opção de estudo. As escalas diagramáticas orientam na estimativa visual de modo que a avaliação torne-se mais precisa e acurada (1).

Para a elaboração da escala diagramática, 50 maracujás amarelos 'Afruvec', com ampla variação de severidade da antracnose, foram coletados em mercados varejistas de Bauru-SP. A face externa de cada fruto, levando em consideração o seu posicionamento na planta, foi fotografada com câmara digital. As imagens digitalizadas foram transferidas para um microcomputador e com auxílio do programa QUANT v.1.0, foram determinadas a área total e a área lesionada do fruto, obtendo-se a severidade da doença. Os níveis mínimo e máximo de severidade foram determinados de acordo com a freqüência observada nos frutos e, níveis intermediários, seguindo incrementos logarítmicos. Depois de estabelecidas as porcentagens de doença a serem representadas na escala, reproduziu-se o desenho de um fruto de maracujá com área conhecida, no qual acrescentaram-se desenhos 
Tabela 1. Intercepto $(a)$, coeficiente angular da reta $(b)$ e coeficiente de determinação $\left(R^{2}\right)$ de equações de regressão linear calculadas entre severidade real e severidade estimada da antracnose em frutos de maracujá amarelo realizadas por avaliadores, sem e com o auxílio da escala diagramática.

\begin{tabular}{|c|c|c|c|c|c|c|}
\hline \multirow[t]{2}{*}{ Avaliador } & \multicolumn{3}{|c|}{ Sem escala } & \multicolumn{3}{|c|}{ Com escala } \\
\hline & $a$ & $b$ & $R^{2}$ & $a$ & $b$ & $R^{2}$ \\
\hline \multicolumn{7}{|c|}{ Inexperientes } \\
\hline 1 & $-2,10$ & $0,75 * *$ & 0,78 & $-3,63 *$ & $0,87 * *$ & 0,90 \\
\hline 2 & $15,46 * *$ & 0,91 & 0,59 & $6,05^{*}$ & 0,91 & 0,84 \\
\hline 3 & $10,27^{*}$ & 0,94 & 0,66 & 0,23 & $0,86 * *$ & 0,90 \\
\hline 4 & 5,72 & 0,92 & 0,65 & 1,74 & 0,93 & 0,89 \\
\hline 5 & 2,89 & $0,81 * *$ & 0,75 & $5,5^{*}$ & 0,92 & 0,88 \\
\hline \multicolumn{7}{|c|}{ Experientes } \\
\hline 6 & $-2,18$ & $0,68 * *$ & 0,80 & 0,39 & $0,88 * *$ & 0,91 \\
\hline 7 & $11,7 * *$ & 1,03 & 0,90 & $-2,23$ & 0,92 & 0,89 \\
\hline 8 & $-2,37$ & 0,93 & 0,83 & $-1,97$ & 0,97 & 0,94 \\
\hline 9 & 0,22 & 0,91 & 0,81 & $-2,76$ & 1,05 & 0,93 \\
\hline 10 & $8,88^{*}$ & 0,89 & 0,71 & $-1,2$ & 1,00 & 0,87 \\
\hline Todos & 4,85 & $0,88^{*}$ & 0,64 & 0,21 & 0,93 & 0,87 \\
\hline
\end{tabular}

* Asterisco indica que a hipótese de nulidade $(a=0$ e $b=1)$ foi rejeitada pelo teste $t(p<0,05)$

** Asterisco indica que a hipótese de nulidade $(a=0$ e $b=1)$ foi rejeitada pelo teste $t(p<0,01)$

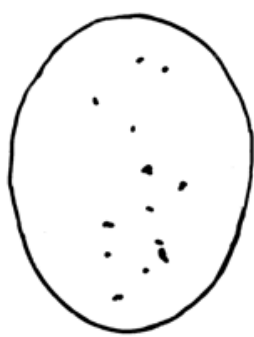

$1 \%$

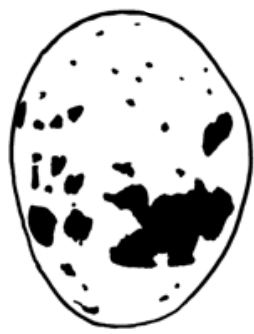

$21 \%$

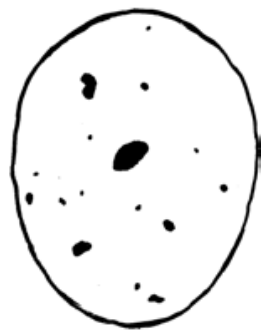

$3 \%$

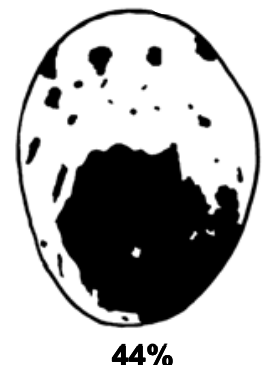

$44 \%$

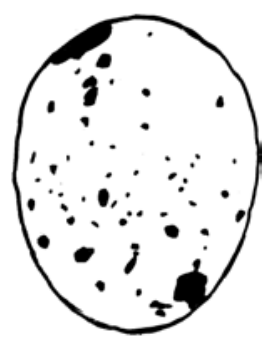

$8 \%$

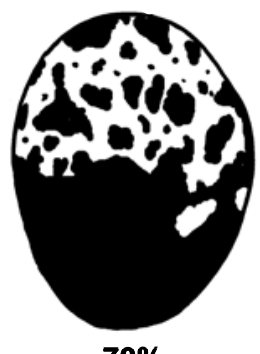

$70 \%$
Figura 1. Escala diagramática para avaliação da severidade (\%) da antracnose (Colletotrichum gloeosporioides) do maracujá amarelo (Passiflora edulis f. flavicarpa).

de lesões, distribuídos de maneira a retratar os sintomas.

Para validar a escala, dez avaliadores, cinco inexperientes e cinco experientes, estimaram a severidade da antracnose a partir de 50 frutos com sintomas em diferentes intensidades. Primeiramente, os avaliadores estimaram a severidade sem a escala diagramática e, em uma segunda fase, estimaram a severidade com o auxílio da mesma.

A acurácia e a precisão de cada avaliador foi determinada por meio da regressão linear entre a severidade real e a severidade estimada (4). A acurácia das estimativas de cada avaliador e do conjunto de avaliadores foi determinada pelo teste $\mathrm{t}$ aplicado ao intercepto da regressão linear (a), para verificar a hipótese Ho: $a=0$, e ao coeficiente angular da reta (b), para testar a hipótese Ho: $b=1(\mathrm{p}<0,01)$. Valores de intercepto significativamente diferentes de 0 indicam a presença de desvios constantes, enquanto valores de coeficiente angular da reta que diferem de 1 indicam desvios sistemáticos. A precisão das estimativas foi obtida pelo coeficiente de determinação da regressão $\left(R^{2}\right)$ e pelos erros absolutos (severidade estimada menos real) $(2,5)$. A reprodutibilidade das estimativas foi determinada pelos valores de $R^{2}$ obtidos de regressões lineares entre as severidades estimadas por diferentes avaliadores combinados em pares (5).

O valor máximo de severidade da antracnose em frutos de maracujá coletados em mercados varejistas foi de $70 \%$. Valores superiores podem ocorrer em frutos armazenados por longos períodos, estes já bastante depreciados para a comercialização. A escala diagramática para quantificação da antracnose do maracujá foi elaborada com seis níveis de severidade, representados pelos valores $1,3,8,21,44$ e $70 \%$, respeitando as limitações da acuidade da vista humana, definidas pela lei de Weber-Fechner (8) (Figura 1).

Quando a severidade da doença foi estimada sem a escala diagramática, a precisão foi relativamente baixa, com $R^{2}$ para as retas de regressão entre severidade real e estimada variando de 0,59 a 0,78 para os avaliadores inexperientes e de 0,71 a 0,90 para os experientes, com média obtida pela regressão conjunta de todos os avaliadores de 0,64 (Tabela 1). Quatro avaliadores foram pouco acurados, pois superestimaram consistentemente a severidade da doença, com valor médio do intercepto ( $a$ ) de todos os avaliadores de 4,85. Outros estudos indicam que a tendência em superestimar valores é mais freqüente e pode ser reduzida com o uso da escala diagramática $(3,6)$. O coeficiente angular da reta de regressão $(b)$ foi de 0,88 na média, estatisticamente menor que $1(\mathrm{p}<0,05)$ (Tabela 1$)$. A distribuição dos resíduos das avaliações realizadas sem a escala apresentou estimativas com erros absolutos variando entre os avaliadores inexperientes de $-47,6$ a 47,8, e entre $-44,0$ a 53,1 para os experientes, sendo a média dos erros (em módulo) dos avaliadores igual a 12,5 e 10,8, respectivamente.

Com a utilização da escala, a maioria dos avaliadores melhorou os níveis de acurácia e precisão das estimativas de severidade da antracnose (Tabela 1). Os coeficientes de determinação entre avaliadores inexperientes variou de 0,84 a 0,90, e entre experientes de 0,87 a 0,94, com média de todos de 0,87 , assemelhando-se ao verificado em outros 
estudos de validação de escalas $(3,6)$. O valor médio da interseção da regressão $(a)$ foi de 0,21 , indicando a redução dos erros verificados sem a utilização da escala. $O$ valor médio do coeficiente angular da reta (b) de 0,93 , foi estatisticamente igual a 1,0, indicando a redução significativa dos erros sistemáticos das estimativas e melhoria na acurácia das estimativas.

Houve redução nos erros absolutos para as estimativas com auxílio da escala, comparada com a distribuição dos erros obtidos sem escala diagramática. Os erros absolutos variaram entre os avaliadores inexperientes de $-18,6$ e 28,8, e entre $-21,8$ a 28,2 para os experientes, sendo a média dos erros (em módulo) dos avaliadores igual a 7,2 e 6,0, respectivamente. A presença de algum nível de erro absoluto nas mensurações pode ser compensada pela rapidez e padronização propiciadas pelo uso de escalas diagramáticas (9). Além disso, como a maioria dos métodos de quantificação de severidade de doenças, o uso de escalas diagramáticas está sujeito a um certo grau de subjetividade, o que pode ser minimizado com o treinamento dos avaliadores (8).

Os $R^{2}$ das equações de regressão linear calculadas nas comparações das estimativas dos avaliadores entre si foram menores sem a utilização da escala diagramática, variando de 0,34 a 0,86 , sendo que somente $26,7 \%$ dos casos foi $\geq 0,75$. Por outro lado, com a utilização da escala as avaliações apresentaram maiores $R^{2}$, variando entre 0,74 a 0,92 , sendo $\geq 0,75$ em $97,8 \%$ dos casos, assemelhando-se ao constatado na valiadação de escalas diagramáticas para outros patossistemas $(3,6)$. Do ponto de vista prático, o uso da escala diagramática aumenta a reprodutibilidade das estimativas obtidas por diferentes avaliadores e, portanto, a estimativa da severidade da doença poderá ser feita por qualquer avaliador, pois os resultados serão semelhantes e diferentes experimentos, conduzidos por avaliadores distintos, serão comparáveis.

A utilização da escala diagramática permitiu quantificar os sintomas da antracnose em frutos de maracujá de maneira acurada e precisa.
Estes resultados sugerem que o seu uso em estudos epidemiológicos poderá proporcionar informações mais realistas a respeito do patossistema C. gloeosporioides - maracujá, assim como, melhores avaliações de diferentes estratégias de controle da antracnose.

\section{REFERÊNCIAS BIBLIOGRÁFICAS}

1. Amorim, L. Avaliação de doenças. In: Bergamin Filho, A.; Kimati, H.; Amorim, L. Manual de fitopatologia. São Paulo: Ceres, 1995. v. 1, cap. 32 , p. 647-671.

2. Campbell, C. L.; Madden, L. V. Introduction to plant disease epidemiology. New York: John Wiley, 1990. 532 p.

3. Díaz, C. G.; Bassanezi, R. B.; Bergamin Filho, A. Desenvolvimento e validação de uma escala diagramática para Xanthomonas axonopodis pv. phaseoli em feijoeiro. Summa Phytopathologica, Botucatu, v. 27, n. 1, p. 35-39, 2001

4. Draper, N. R.; Smith, H. Applied regression analysis. 3th ed. New York: John Wiley, 1998. 706 p.

5. Kranz, J. Measuring plant disease. In: Kranz, J.; Rotem, J. Experimental techniques in plant disease epidemiology. Berlin: Springer, 1988. p. 35-50.

6. Leite, R. M. V. B. C.; Amorim, L. Elaboração e validação de escala diagramática para mancha de Alternaria em girassol. Summa Phytopathologica, Botucatu, v. 28, n. 1, p. 14-19, 2002.

7. Liberato, J. R. Controle das doenças causadas por fungos, bactérias e nematóides em maracujazeiro. In: Zambolim, L.; Vale, F. X. R. do; Monteiro, J. A.; Costa, H. Controle de doenças de plantas: Fruteiras. Viçosa: UFV, 2002. p. 699-825.

8. Nutter, F. W., Jr.; Schultz, P. M. Improving the accuracy and precision of disease assessments: selection of methods and use of computer-aided training programs. Canadian Journal of Plant Pathology, Ottawa, v. 17, n. 1, p. 174-184, 1995.

9. Stonehouse, J. Assessment of Andean bean diseases using visual keys. Plant Pathology, London, v. 43, n. 3, p. 519-527, 1994. 